\title{
Minimally Invasive Parathyroidectomy in Primary Hyperparathyroidism : A Mini-Review
}

\author{
Michael AB Naafs* \\ Naafs International Health Consultancy, Europe
}

Submission: December 01, 2017; Published: December 11, 2017

*Corresponding author: Michael AB Naafs, Internist-endocrinologist with a long clinical career in internal medicine and endocrinology, Naafs International Health Consultancy, Europe, Email: naafsmichael@gmail.com

\begin{abstract}
In this mini-review the evolution of minimally invasive parathyroidectomy (MIP) in patients with primary hyperparathyroidism (PHP) during the last two decades,is discussed.Old and new localization techniques for identifying parathyroid adenomas,including high-resolution ultrasound,sestambi scanning and its SPECT/CT modifications,intraoperative PTH measurements (IOPTH) and radioguided parathyroidectomy are reviewed. Ultrasound and conventional sestambi scanning result in a correct localization in $85 \%$ of patients. MIP results then in $98-99 \%$ cure rates in PHP patients.This 30-45 minutes procedure can be performed as a daycase care,even under local anesthesia,without sedation.Cosmesis is optimal,operating time,length of hospital stay,costs and postoperative temporary hypocalcemia are reduced by $50 \%$,compared to conventional bilateral neck exploration.The fear of recurrent laryngeal nerve damage caused a shift from the general surgeon to the ENT surgeon,as the prefered endocrine neck surgeon.This has been proven unfairly,as recurrent laryngeal nerve damage is extremely rare in MIP.There is no place for SPECT/CT sestambi scanning,CT and 3-or 4 dimensional CT or MRI in the initial diagnostic work-up of PHP patients.Exclusion of these modalities from routine parathyroid imaging protocols, saves the patient from unnecessary radiation exposure and imaging time.In 20 years MIP has been settled definitely ,as the procedure of first choice in the surgical management of patients with primary hyperparathyroidism.
\end{abstract}

Abbreviations: MIP: Minimally Invasive Parathyroidectomy; PHP: Primary Hyperparathyroidism; MIVAT: Minimally Invasive Video-Assisted Thyroidectomy ; MIVAP: Minimally invasive video-assisted parathyroidectomy ; BNE : Bilateral Neck Exploration; PTH : Excessive Parathyroid Hormone.

\section{Introduction}

Since the late 1980's, when the first laparoscopic cholecystectomies were performed,minimally nvasive surgical techniques have gained interest among all surgical specialties. Endoscopic surgery has been limited to procedures performed in the thorax and abdominal cavity for a long time, because these areas have a pre-existing cavity or space in which to work. It was in the late 1990's, when minimally invasive videoassisted thyroidectomy (MIVAT) was introduced in clinical practice by Miccoli et al. [1]. Minimally invasive video-assisted parathyroidectomy (MIVAP) followed soon [2]. Now, 20 years later the development of various ultrasound-guided and endoscopiv video-assisted and robotic surgical techniques have changed the approach to thyroid and parathyroid diseases. In this mini-review the various techniques,selection of patients, preoperative imaging studies, intra-operative parathyroid gland identification and parathyroid hormone sampling,results and complications in PHP patients, as well as the shift to the ENT surgeon as an endocrine neck surgeon will be discussed. Finally the cost- benefit analysis will be considered.

\section{Minimally Invasive Parathyroid Surgery (MIP)}

a) Localization studies: Bilateral neck exploration (BNE) with the identification of at least 4 parathyroid glands and removal of pathological parathyroid tissue has been the standard treatment for more than 60 years. These operations had a cure rate of more the $95 \%$,with a morbidity less than 3\% [3]. Most primary hyperparathyroidism (PHP) patients (85\%) have a single parathyroid adenoma, responsible for excessive parathyroid hormone (PTH) production [4]. If this could be located correctly parathyroid adenectomy is an ideal candidate for an unilateral surgical approach. Localization studies were performed in the last century,with the use of thallium-technetium subtraction scans. Parathyroid imaging was useful in $50 \%$ of cases and less effective in demonstrating multiple gland hyperplasia [5].

Although the indication for parathyroidectomy is settled by the clinical symptoms and biochemical evaluation,new localization techniques, as high-resolution ultrasound (HR-US), sesta [6] MIBI (MethoxylIsobutyl Isonitrile) scintiscan and the introduction of 
the rapid intra-operative PTH (IOPTH) assay gave a push to the development of MIP [6-8]. Surgeons prefer to have a localization study before an operation. They are not satisfied by having referred a patient with just a biochemical diagnosis of PHP.

\section{High-resolution ultrasound in PHP}

HR-US represents together with nuclear medicine imaging,a reiable first line modality for preoperative localization of a parathyroid adenoma. Neck-US is performed with a high-frequency (7, 5-15 MHz) transducer to enhance spatial resolution, allowing detection of glands larger than $5 \mathrm{~mm}$ [9]. Colour-Doppler assessment is a useful integration for the distinction of parathyroid adenomas from other cervical lesions,thus reducing falsepositive findings [10]. HR-US has a sensitivity of around $85 \%$ in experienced hands [11]. HR-US is mostly combined with sestambi scintigraphy.Smith et al. evaluated this combination in preoperative localization for parathyroid surgery $(n=220)$. Preoperative ultrasonography,sestambi scintigraphy or both were obtained in $77 \%, 93 \%$ and $69 \%$ of the patients respectively. Preoperative ultrasonography and sestambi scintigraphy localized an abnormality in $71 \%$ and $79 \%$ of the patients respectively. Accuracy of localization was $82 \%$ for US and $85 \%$ for sestambi scintigraphy. In patients with inaccurate ultrasound localization, the sestambi scintigraphy correctly identified the site of disease in only $45 \%$. In patients with a non localizing ultrasound, sestambi scintigraphy was able to localize disease in only $47 \%$,with two adenomas being in the mediastinum [11].

\section{Sestambiscan and sestambi-SPECT/CT}

MIBI scanning (double phase) is still the favourite procedure for localizing parathyroid adenomas,including double adenomas and ectopic mediatinal adenomas.MIBI scanning reaches a sensitivity of $90 \%$,when combined with SPECT (single-photon emission computed tomography) or SPECT/CT.Studies comparing newer tracers, such as 11C-methionine and CT techniques are small however, allowing no other conclusion than that techniques are very expensive and are not standardized, yet. Their value above conventional sestambi scintigraphy in combination with cheap ultrasound is not proven [12]. In a pooled meta-analysis of 23 studies $(n=1236)$ the detection rate of 99mTc-MIBI SPECT/ CT in the preoperative planning of patients with PHP was $88 \%$ (95\%CI;84\%-92\%) and $88 \%$ on a per patient per lesion-based analysis,respectively [13]. This is not much better, than the sensitivity of sestambi scintigraphy alone [11]. Gayed et al. could not find an additional benefit of SPECT/CT in identifying diseased parathyroid glands $(n=48)$. Exclusion of the CT part from the routine parathyroid imaging protocol saves the patient from unnecessary radiation exposure and imaging time [14].

\section{Unilateral MIP}

Most surgeons favour a minimally invasive parathyroidectomy. The frequency of multiglandular disease is however still a matter of debate, ranging from $5 \%$ in small series up to $30 \%$ in large series of parathyroidectomy. Probably this reflects a referral bias [15-
17]. Peel et al. [16] could discharge 101 of 154 patients the same day after performing an unilateral MIP. Reasons for an overnight hospital were distance and available home care. Anesthesia could be administered locally in combination with short i.v sedation, cosmesis was fine with a $2-4 \mathrm{~cm}$ incision and hospital costs and operating time were reduced by $50 \%$ [16]. A Mayo Clinics cohort analysis of 1361 patients showed equally cure rates for MIP and conventional bilateral parathyroidectomy (97\%). Multiglandular disease was present in $16 \%$ of the patients,which was identified successfully, by performing intraoperative PTH measurements.The main reasons for not-performing a MIP were, neck operations due to prior thyroidectomy and inadequate or conflicting localization or multiglandular disease [18].

\section{Intra-operative PTH assay}

Minimally invasive parathyroidectomy relies on careful preoperativ localization procedures to identify the solitary parathyroid adenoma and on intraoperative PTH (IOPTH) monitoring. PTH has a very short half-life of 3-5 minutes [19]. IOPTH monitoring involves sampling of PTH values, preoperative and intra-operatively, and after resection of abnormal parathyroid glands. The definition of a succesful parathyroidectomy, utilizing IOPTH data varies by institution. Two common criteria include; a decrease of $>50 \%$ from the highest pre-excision value, the Miami criterion,or a decrease of $>50 \%$ of the highest pre-excision value, with a return into the normal range of the PTH assay [20-22]. The test often takes up to 30 minutes, which prolongs the operating time, especially in cases in which the PTH level does not fall. Many experienced surgeons get impatient then, because they could perform a bilateral exploration, during the time it took to get the PTH report back. One of the main reasons for Norman et al. to abandon the unilateral parathyroidectomy and the IOPTH measurements [17]. If the 5-minute IOPTH level does not drop 50\%, the surgeon must either wait for more IOPTH levels or continue furher operative exploration, which can be time consuming [23].

Alheldi et al evaluated 1021 patients, 817 patients with a single adenoma(SA) (83,2\%), 99(10\%) with a double adenoma (DA) and $78(7,6 \%)$ with hyperplasia (HA). SA patients exhibited $56,6+/-4,9 \%$ decline in IOPTH levels at 5 -minutes, compared to $21,3+/-4,5 \%$ in DA and 22, 5+/-4,3\% in the HA Group ( $\mathrm{p}<0,01)$. Post hoc comparisons revealed, that the 5-minute decrease in the SA group was significantly greater, than either in the DA or HA groups $(\mathrm{p}<0,01)$. A 5 -minute percentage decline of $35 \%$ best distinguished SA from multiglandular disease $(85,3 \%$ vs $24,9 \%)$. They concluded,that when IOPTH does not drop at least 35\% at 5-minutes post-excision, the surgeon should consider further exploration, rather than waiting for additional IOPTH levels [24]. Other institutions use baseline IOPTH from a peripheral blood sample following anesthesia induction, at adenoma resection(zero value) and 5, 10 and 15 minutes postexcision. A 50\% drop in IOPTH levels, with return in the reference range of the IOPTH assay (mostly Nichols Diagnostics Products Corporation, LA, CA or Roche Diagnostics, Indianapolis,IN), is considered a successful parathyroidectomy [19]. 


\section{Minimally Invasive Radioguided Parathyroidectomy (MIRP)}

MIRP uses a gamma detection probe for identifying parathyroid adenomas during surgery, alone or in combination with IOPTH measurements. Technetium $(99 \mathrm{mTc})$ sesta MIBI is used as a radiotracer for intraoperative localization of adenomatous parathyroid glands. The injection is usually given 2-3 hours before surgery, because the tracer washes out more quickly from the thyroid than from the parathyroids. Disturbances in parathyroid imaging by thyroid uptake are avoided as much as possible in this way. The lapse of time of time useful to perform surgery is therefore narrow and strict [25]. Several protocols have been developed. Some perform the sesta MIBI scan on the day of surgery and surgery 3 hours later. Others use a separate day double tracer subtraction scintygraphy protocol, with a low dose injection of the tracer $99 \mathrm{mTc}$ sesta MIBI some minutes before the start of the surgery $[26,27]$.

Another method is blocking the uptake of the tracer by the thyroid, through administration of Lugol's solution during 4 days before surgery. On the day of surgery the patient undergoes sesta MIBI scanning. An ex vivo radioactivity count by the handheld gamma probe of the adenoma $20-40 \%$ greater than the value of the background activity is accepted as an identified adenoma. The authors show nice pictures, but do not mention the number of examined patients [28]. Mehrabibahar et al. [29] evaluated 87 patients with previous neck US and MiBI scan, performing radioguided surgery. IOPTH monitoring was not used.One $\mathrm{mCi}$ MIBI was injected in the operating room before the beginning of the surgery. MIRP was successfully performed in 86 of 87 patients. The gamma probe was particularly useful in detection of an ectopic parathyroid adenoma in the upper mediastinum. Mean operation time was 24 minutes and the mean hospital stay was 1, 5 day. Radiation exposure was 20 times lower, than using the conventonal $20 \mathrm{mCi} 99 \mathrm{mTc}-\mathrm{MIBI}$. Frozen section tissue samples for parathyroid adenoma identification were not used. Mean follow-up of 6 months showed no complications or recurrences.

\section{Frozen section identification in MIP}

With the advent of HR-US,sestambi scanning,IOPTH monitoring and sometimes radioguided parathyroidectomy, identification of parathyroid adenomas and hyperplasia by frozen section tissue samples has become uncommon. Dewan et al. showed in 50 parathyroidectomies, that gross examination was disconcordant with the frozen section pathology examination in only 3 patients $(6 \%)$. The decision to omit intraoperative frozen section examination must be balanced against the implications of misdiagnosis and a repeat operative procedure [30].

\section{CT and MRI in parathyroid imaging}

These modalities have no place in the initial evaluation of parathyroid pathology. Both modalities have applications in complex cases, as in the reoperative setting,or in the rare presence of parathyroid carcinoma (1\%) [31].

\section{Complications of MIP and Cost-Effectiveness}

In a prospective randomized controlled trial $(n=91)$,unilateral neck exploration yielded the same cure rates and histology as the bilateral approach. However patients in the bilateral group had a higher incidence of early symptomatic hypocalcemia (28\% vs $49 \%$ ),consumed more oral calcium and had lower serum calcium levels postoperatively, compared with the unilateral group. Apart from the reduced risk of hypocalcemia MIP offered a 50\% reduction in operating time, a reduced length of hospital stay nd a $50 \%$ reduction in cost with a mean cost saving of $\$ 2693$ per patient [15,32] Udelsman et al. [33] found MIP being superior to conventional parathyroidectomy, based on their results of 1650 consecutive patients with primary hyperparathyroidism. MIP had a cure rate of $99,4 \%$ and a complication rate of $1,45 \%$ vs $97,1 \%$ cure rate and $3,1 \%$ complication rate for conventional, bilateral parathyroidectomy. MIP resulted in a shorter hospital stay and less costs [33].

Karahan et al. [34] evaluated 49 patients with PHP,who underwent MIP under local anesthesia,without any sedation. During MIP gamma probe identification was used for all patients. Of the 49 patients 47 were totally cured. In 2 patients the procedure was switched to conventional bilateral neck exploration. In a UK series of 59 patients with MIP for PHP 53 patients were discharged the same day. Ten percent had an overnight stay for temporary hypocalcemia correction [35]. Bleeding and infection are extremely rare complications in MIP,as is damage to the recurrent laryngeal nerve $[35,36]$. In contrast to,for example MIVAT intraoperative electrophysiological monitoring of the recurrent laryngeal nerve during MIP is mostly considered as "overdone" [37]. Nevertheless the fear of recurrent laryngeal nerve damage has been the main reason for a shift from the general surgeon to the ENT surgeon as an endocrine neck surgeon.

\section{Conclusion}

In 20 years MIP has been settled definitely,as the procedure of first choice in the surgical mamagement of patients with PHP. It is a safe and efficacious short procedure. Costs,operating time, length of hospital stay and temporarary postoperative hypocalcemia are reduced by $50 \%$. Cosmesis is optimal, as is patient satisfaction. MIP can be performed on a day case care under local anesthesia, with or without sedation. Ultrasound, sestambi scanning,combined with IOPTH measurements or nuclear mapping, result in cure rates of $98-99 \%$.Actually no other complications than postoperative temporary hypocalcemia are seen (10-20\%). Bleeding, infection and recurrent laryngeal nerve damage are rare. There is no place for SPECT/CT sestambi scanning and 3 or 4 dimensional CT or MRI in the initial diagnostic work-up of PHP patients. Exclusion of these modalities from routine parathyroid imaging saves the patient from unnecessary radiation exposure and imaging time. Both general and ENT surgeons can perfom MIP safely, with a presumed minimum in the literature of 30 procedures a year. Both MIP and conversion to bilateral neck exploration should be trained. 


\section{Global Journal of Otolaryngology}

\section{References}

1. Miccoli P, Berti P, Raffaelli M, Conte M, Materazzi G, et al. (2001) Minimally invasive video-assisted thyroidectomy. Am J Surg 181(6): 567 570.

2. Lorenz K, Nguyen-Than H, Dralle H (1999) First experience with minimally invasive video-assisted parathyroidectomy. Acta Chir Austriaen 31(4): 218-220.

3. Duh QY (1997) Surgical approach to primary hyperparathyroidism (bilateral approach). Clark O.H., Duh Q.Y.,eds. In: Textbook of Endocrine Surgery,Philadelphia,W.B. Saunders, pp357-363.

4. Madkhali T, Alheldi A, Chen H (2016) Primary Hyperparathyroidism. Ulus Cerrahi Derg 32: 58-66.

5. Samanta A, Wilson B, Igbal J (1990) A clinical audit of thallium-technetium subtraction parathyroid scans. Postgrad Med J 66(776): 441-445.

6. Mazzeo S, Caramella D, Lencioni R (1996) Comparison among sonography,double-tracer subtraction scintigraphy and double phase scintigraphy in the detection of parathyroid lesions. AJR 166: 1465-1470.

7. Irvin GL, Carneiro DM (1999) Rapid parathyroid hormone guided exploration. Op Tech Gen Surg 1: 18-27.

8. Lee JA, Inabet WA (2004) The surgeons armamentarium in the surgical treatment of primary hyperparathyrodism. J Surg Oncol 89: 130-135.

9. Kamaya A, Quon A, Jeffrey RB (2006) Sonography of the abnormal parathyroid gland. Ultrasound Quarterly 22: 253-262.

10. Devzic Z, Jeffrey RB, Kamaya A (2013) The elusive parathyroid adenoma: techniques for detection. Ultrasound Quarterly 29(3): 179-187.

11. Smith RB, Evasovich M, Girod DA (2013) Ultrasound for localization in primary hyperparathyroidism. Otolaryngol Head Neck Surg 149(3): 366-371.

12. Martinez-Rodriquez N, Martinez-Amador N, de Arcocha-Torres M (2014) Comparison of 99Tc-sestambi and 11C-methionine PET/CT in the localzation of parathyroid adenomas in primary hyperparathyroidism. Rev Esp Med Nucl Imagen Mol 33(2): 93-98.

13. Treglia G, Schalin-Jäntti CS, Sadeghi R (2016) Detection rate of 99mTC-MIBI SPECT/CT in the preoperative planning of patients with primary hyperparathyroidism: A meta-analysis; 99mTC-MIBI SPECT/ CT in primary hyperparathyroidism. Head and Neck 38: E2159- E2172.

14. Gayed IW, Kim EE, Broussard WF (2005) The value of 99mTC-Sestami SPECT/CT over Conventional SPECT in the Evaluation of Parathyroid Adenomas or Hyperplasia. J Nucl Med 46(2): 248-252.

15. Udelsman R (2002) Six hundred fifty-six consecutive explorations for primary hyperparathyroidism. Ann Surg 235(5): 665-670.

16. Peel JK, Melk AL (2016) Same day discharge after unilateral parathyroidectomy is safe. Can.J Surg 59(4): 242-246.

17. Norman J, Lopez J, Politz D (2012) Abandoning Unilateral Parathyroidectomy:Why We Reversed Our Position After 15.000 Parathyroid Operations. J Am coll Surg 214(3): 260-269.

18. Grant CS, Thompson G, Farley D, Van Heerden J (2005) Primary Hyper parathyroidism Surgical Management Since the Introduction of Minimally Invasive Parathyroidectomy: Mayo Clinic Experience. Arch Surg 140(5): 472-479.

19. Leiker AJ, Yen TW, Eastwood DC, Doffek KM, Szabo A, et al. (2013) Factors that influence parathyroid hormone half-life: Are new intra-operative criteria needed. JAMA Surg 148(7): 602-606.

20. Carneiro DM, Solorzano CC, Nader MC, Ramirez M, Irvin GL (2003) Third comparison of intraoperative iPTH assay (QPTH) criteria in guiding parathyroidectomy: which criterion is the most accurate? Surgery 134(6): 973-979.

21. Richards ML, Thompson GB, Farley DR, Grant CS (2011) An optimal algorithm for intraoperative parathyroid hormone monitoring. Arch Surg 146(3): 280-285.

22. Carty SE, Worsey J, Virji MA, Brown ML, Watson CG (1997) Concise parathyroidectomy: the impact of preoperative SPECT 99mTc sestambi scanning and intraoperative quick parathormone assay. Surgery 122(6): 1107-1114.

23. Mazeh H, Chen H, Leverson G, Sippel RS (2013) Creation of a "Wisconsin Index" Nomogram to Predict the Likelihood of Additional Hyperfunctioning Parathyroid Glands During Parathyroidectomy. Ann Surg 257: 138-141.

24. Alhefdhi A, Ahmad K, Sippel R, Chen H, Schneider DF (2017) Five Minute Intraoperative Parathyroid Levels Can Identify Multigland Disease. Ann Surg Oncol 24(3): 733-738.

25. Mariani G, Gulec SA, Rubella D, Boni G, Manca G, et al. (2003) Preoperative localzation and radioguided parathyroid surgery. J Nucl Med 44(9): 1443-1458.

26. Norman J, Chheda H (1997) Minimally invasive parathyroidectomy facilitated by intraoperative nuclear mapping. Surgery 122(6): 9981003.

27. Rubella D, Piotto A, Casara D (2003) Role of gamma probes in performing minimally invasive parathyroidectomy in patients with primary hyperparathyroidism: optimization of preoperative and intraoperative procedures. Eur J Endocrinol 149(1): 7-15.

28. Pasta V, Montefelone F, DelVecchio L (2015) Original technique for preoperative preparation of patients and intraoperative localization of parathyroid adenomas. G Chir 36(3): 97-100.

29. Mehrabibahar M, Mousavi Z, Sudeghi R, Nouri M, Asadi M, et al. (2017) Feasblity and safety of minmally invasive radioguided parathyroidectomy using very low intraoperative dose of Tc-99m MIBI. Int J Surg 39: 229-233.

30. Dewan AK, Kapadia SB, Hollenbeak CS, Stack BC (2005) Is Routine Frozen Section Necessary for Parathyroid Surgery? Otolaryngol Head Neck Surg 133(6): 857-862.

31. Warren Frunzac R, Richards M (2016) Computed Tomography and Magnetic Resonance Imaging of the Thyroid and Parathyroid Glands. In: Imaging in Endocrine Disorders Front Horm Res Basel Karger 45: $16-23$

32. Bergenfelz A, Lundblom P, Tibblin S, Westerdahl J (2002) Unilateral versus bilateral neck exploration for primary hyperparathyroidism: a prospective randomized controlled trial. Ann Surg 236: 543-551.

33. Udelsman R, Lin Z, Donovan P (2011) The superiority of minimal invasive parathyroidectomy based on 1650 consecutive patients with primary hyperparathyroidism. Ann Surg 253(3): 585-591.

34. Karahan O, Okus A, Sevinc B (2013) Minimal invasive parathyroidectomy under local anesthesia. J Postgrad Med 59(1): 21-24.

35. Sawant R (2017) Parathyroidectomy as a Daycase Surgery: Retrospective Study. J Med Dent Sci Res 4(2): 27-31.

36. Rajeev P, Stechman MJ, Kirk H (2013) Safety and efficacy of minimally invasive parathyroidectomy (MIP) under local anaesthesia without intraoperative PTH measurement. Int J Surg 11(3): 275-277.

37. Poveda MC, Diongi G, Sitges-Serra A (2011) Intraoperative Monitoring of the Recurrent Laryngeal Nerve during THyroidectomy: A Standardized Approach (Part1). World J Endocr Surg 3(3): 144-150. 

(C) This work is licensed under Creative BY DOI: $10.19080 /$ GJ0.2017.12.555831
Your next submission with Juniper Publishers will reach you the below assets

- Quality Editorial service

- Swift Peer Review

- Reprints availability

- E-prints Service

- Manuscript Podcast for convenient understanding

- Global attainment for your research

- Manuscript accessibility in different formats

( Pdf, E-pub, Full Text, Audio)

- Unceasing customer service

Track the below URL for one-step submission https://juniperpublishers.com/online-submission.php 